\title{
ARTÍCULOS
}

\section{¿GUERRA ANTICOLONIAL O GUERRA CIVIL? ANÁLISIS HISTORIOGRÁFICO SOBRE EL PROTAGONISMO ÉTNICO EN LA INDEPENDENCIA DEL ECUADOR SEGÚN LOS TEXTOS ESCOLARES DE HISTORIA (1915-2015).}

\author{
Víctor H. Silva Guijarro \\ Universitad Nacional de Educación a Distancia \\ vsilvaguijarro@gmail.com
}

\begin{abstract}
Resumen: El presente trabajo consiste en un análisis historiográfico sobre el protagonismo que tuvieron los distintos grupos étnicos en la Guerra de Independencia del Ecuador según los textos escolares de Historia publicados entre 1915 y 2015. Se han utilizado como fuentes historiográficas los textos escolares de Historia, debido a que desde el siglo XX las políticas educativas ecuatorianas los han utilizado como instrumentos ideológicos para llevar a cabo la construcción de una identidad nacional común cimentada a partir de los presupuestos de la Historia Patria del siglo XIX. El empleo de la enseñanza de la Historia a través de los textos escolares para consolidar esa identidad nacional del siglo XIX se hace patente en el análisis sobre el protagonismo étnico en la Independencia, donde dichos textos explican este acontecimiento como un proyecto de construcción nacional dirigido por las élites criollas cuyo supuesto objetivo principal era liberar a todos los "ecuatorianos" de una presunta opresión monárquica ejercida por un enemigo extranjero: el "español". Pese a que hay autores que han manifestado que indígenas, negros, mestizos, zambos, pardos, mulatos, cholos, obtuvieron pocos beneficios de la Independencia, todos los textos escolares no dudan en confirmar que gracias a los esfuerzos de las élites criollas, héroes de la Patria a los que hay que venerar y ensalzar, la República del Ecuador pudo ser libre.
\end{abstract}

Palabras clave: Textos escolares, Historia Patria, protagonismo étnico, Guerra de Independencia, Estado-Nación, identidad nacional.

Tittle: ANTI-COLONIAL WAR OR CIVIL WAR? HISTORIOGRAPHIC ANALYSIS OF THE ETHNIC PROTAGONISM IN THE INDEPENDENCE OF ECUADOR ACCORDING TO THE HISTORY TEXTBOOKS (1915-2015).

Abstract: The present work consists of a historiographic analysis of the protagonism that the different ethnic groups had in Ecuador's War of Independence according to the history textbooks published between 1915 and 2015. History school textbooks have been used as historiographic sources, because since the 20th century Ecuadorian educational policies have used them as ideological instruments to carry out the construction of a common national identity based on the assumptions of the 19th century Patriotic History. The use of the teaching of history through school texts to consolidate this 19th century national identity is evident in the analysis of the ethnic protagonism in the Independence, where these texts explain this event as a project of national construction directed by the Creole elites whose supposed main objective was to free all "Ecuadorians" from an alleged monarchical oppression exercised by a foreign enemy: the "Spanish". Although some authors have stated that indigenous people, blacks, mestizos, zambos, pardos, mulatos and cholos obtained few

Recibido: 14-01-2021

Aceptado: 25-01-2021

Cómo citar este artículo: SILVA GUIJARRO, Víctor H. ¿Guerra anticolonial o guerra civil? Análisis historiográfico sobre el protagonismo étnico en la independencia del Ecuador según los textos escolares de Historia (1915-2015). Naveg@mérica. Revista electrónica editada por la Asociación Española de Americanistas [en línea]. 2021, n. 27. Disponible en: $<$ http://revistas.um.es/navegamerica>. [Consulta: Fecha de consulta]. ISSN 1989-211X. 
Víctor H. SILVA GUIJARRO. ¿Guerra anticolonial o guerra civil? Análisis historiográfico sobre el protagonismo étnico en la independencia del Ecuador según los textos escolares de Historia (19152015).

benefits from Independence, all the school texts do not hesitate to confirm that thanks to the efforts of the Creole elites, heroes of the country who are to be venerated and praised, the Republic of Ecuador was able to be free.

Keywords: Textbooks, Homeland History, ethnic protagonism, War of Independence, Nation-State, national identity.

\section{Introducción}

Desde el momento en el que los libertadores criollos obtuvieron la victoria en la Guerra de Independencia, el siguiente paso de los líderes de las nacientes republicas fue poner en marcha la construcción del Estado-nación como nuevo sistema político hegemónico. Este contexto obligó a los arquitectos de las nacientes patrias a crear y demostrar la existencia de la nación mediante la creación de una identidad nacional imaginada que llevara a cabo una diferenciación entre un "ellos" y un "nosotros"1. En el caso del Ecuador, tras su afianzamiento como República el principal objetivo de las élites dirigentes, representantes de una nación que había que imaginarla, construirla y extenderla ${ }^{2}$, fue el de arraigar y legitimar en el imaginario de los ecuatorianos el prototipo de nación y de identidad que querían construir mediante la consolidación de una personalidad nacional única y una trayectoria histórica común. Una de las herramientas empleadas para hacer realidad esta empresa fue la educación nacional, la cual debía sustituir a la educación estamental del siglo XVIII ${ }^{3}$. Dentro de esta educación, la enseñanza de la Historia Patria desempeñó un papel clave, ya que la cultura escolar del siglo XIX la utilizó para emprender esa construcción identitaria ${ }^{4}$. Los textos escolares de Historia, como instrumentos idóneos para transmitir esos nuevos valores, cobran por tanto una singular importancia como fuentes para el estudio de la construcción nacional del país.

Desde el siglo XIX los "Padres de la Patria" comprendieron que el triunfo definitivo de su proyecto se encontraba en dar cuerpo a lo que Pérez Vejo ha definido como una "construcción erudita difundida por grupos especializados en el imaginario de una comunidad"; nos referimos a la nación ${ }^{5}$. Es en este contexto donde los poderes políticos han utilizado la Historia Patria como una disciplina escolar para llevar a cabo una síntesis y transformación del proyecto de Estadonación de las élites criollas en un objeto de enseñanza con la finalidad de insertar en los ciudadanos la conciencia de pertenencia a una nueva nación y generar un sentimiento de lealtad y confianza en las instituciones públicas. Esta situación no es producto del pasado puesto que los nacionalismos actuales siguen empleando la

\footnotetext{
1 PÉREZ VEJO, Tomás. Nación, identidad nacional y otros mitos nacionalistas. Oviedo: Ediciones Nobel, 1999 , p. 44.

2 PÉREZ VEJO, Tomás. España imaginada: historia de la invención de una nación. Barcelona: Galaxia Gutenberg, 2015, pp. 10-16.

3 OSSENBACH, Gabriela. Formación de los sistemas educativos nacionales en Hispanoamérica. El caso ecuatoriano, 1895-1912. Quito: Corporación Editorial Nacional, 2018, pp. 65-71.

${ }^{4}$ BOYD, Carolyn P. Historia Patria. Política, historia e identidad nacional en España: 1875-1975. Barcelona: Ediciones Pomares-Corredor, 2000, p. 261.

${ }_{5}^{5}$ PÉREZ VEJO, Tomás. España imaginada... Op. cit., p. 12.
} 
enseñanza de la historia por medio de los textos escolares para lograr no tanto la comprensión por parte de los alumnos de los problemas historiográficos, sino más bien inculcarles desde pequeños el "amor a la Patria" y el conocimiento de las glorias nacionales ${ }^{6}$. Es por esta razón que dicha enseñanza ha sido uno de los sectores más codiciados por los gobiernos ya que su control garantiza ser árbitro y creador de la idea de nación?

Este proyecto nacional del siglo XIX ha promovido una enseñanza de la Independencia, presente en los textos escolares, a partir de una explicación imaginada e idealizada de este acontecimiento como un enfrentamiento entre dos naciones e identidades enfrentadas: "nosotros" los ecuatorianos deseosos de libertad, versus "ellos" los españoles tiranos y crueles, que sirvió para cimentar las bases del Estado-nación de las élites criollas. Al ser conscientes de la gran importancia que tiene el texto escolar de Historia en la formación de la opinión pública ecuatoriana y en el desarrollo de la cultura nacional ${ }^{8}$, así como del protagonismo principal que ha desempeñado como elemento promotor de la identidad nacional de los Estados-nación surgidos tras la Independencia, se busca con este análisis colaborar en la puesta en valor del texto escolar no solo como un instrumento para llevar a cabo una nacionalización del pasado y del presente, sino también proponer su utilización como una herramienta que permita estudiar y analizar el pasado desde una perspectiva crítica ${ }^{9}$.

En este trabajo realizaremos un análisis historiográfico para conocer cual es el protagonismo otorgado por los textos escolares a los distintos grupos étnicos en la Guerra de Independencia. No obstante, debemos informar que ante la complejidad que supone combinar la perspectiva étnica donde estarían en juego tres etnias fundamentalmente: nativos amerindios, afroamericanos y blancos con las subdivisiones, de carácter socioeconómico y cultural en el interior de cada una de ellas, en este análisis no buscamos realizar un estudio en profundidad sobre esto. Ya que nuestro principal objetivo consiste en someter a debate la explicación (realizada por los textos escolares) de la Independencia como una supuesta guerra anticolonial que enfrentó a dos naciones e identidades diferentes: Ecuador versus España, con las investigaciones historiográficas académicas sobre este acontecimiento.

\footnotetext{
6 CARRETERO, Mario. La construcción de una identidad nacional. Cuadernos de Pedagogía. 2001, n. 308, p. 53.

7 CRUZ FERNÁNDEZ, Paula de la. Enseñando identidad nacional en el Ecuador. Minius: Revista de Departamento de Historia, Arte e Xeografía. 2008, n. 16, p. 115.

8 AYALA MORA, Enrique. Historiografía ecuatoriana: apuntes para una visión general. Quito: Corporación Editora Nacional, 2015, p. 132.

9 CUESTA, Raimundo. El código disciplinar de la Historia escolar en España: Algunas ideas para la explicación de la sociogénesis de una materia de enseñanza. Encounters in Theory and History of Education. 2002, n. 3, p. 36.
} 


\section{Análisis del protagonismo étnico en la Guerra de Independencia del Ecuador según los textos escolares de Historia ${ }^{10}$}

Con el fin de trazar una hoja de ruta que nos permita cumplir con todos los objetivos propuestos, esta investigación se articulará a partir de una pregunta: ¿cuál fue el protagonismo de los distintos grupos étnicos en la Guerra de Independencia? Esta pregunta será el instrumento a partir del cual se ha buscado conocer y analizar el protagonismo atribuido por los textos escolares a los diversos grupos étnicos (peninsulares, criollos, mestizos, indígenas, negros, zambos, etc.) durante el desarrollo del proceso independentista ecuatoriano. Para responder a esta cuestión se ha estudiado una muestra de quince textos escolares de enseñanza primaria y secundaria publicados entre 1915 y $2015^{11}$. Los resultados de esta investigación se presentan en tres bloques cronológicos diferentes.

\subsection{Criollos y peninsulares como principales protagonistas de la Independencia (1915-1930)}

En las dos primeras obras analizadas de Bruño ${ }^{12}$, la presencia de indígenas, negros y zambos en el estudio de la Independencia es nula, de lo que se desprende su exclusión del proceso independentista. Sin embargo, sí hace una alusión al pueblo en general: "Al amanecer el 10 de agosto de 1809 [...] la guarnición y el pueblo, saliendo a la plaza mayor, lanzaron el grito de Independencia, con música y repiques de campanas..."13. En la Independencia descrita por Cano ${ }^{14}$, destaca nuevamente que criollos y peninsulares son los únicos protagonistas de este acontecimiento ${ }^{15}$.

Uzcátegui ${ }^{16}$ da protagonismo a Eugenio Espejo, el cual es definido como criollo. Además, realiza un breve recorrido por la vida de otros tres personajes criollos considerados como los precursores de la Independencia, estos son: Antonio Ante, Francisco Miranda y Antonio Nariño. En esta obra también se encuentra una evocación a las comunidades indígenas de la época prehispánica y colonial para recordar que el Ecuador es un país con antecedentes libertarios, y pone como ejemplo que las parcialidades indígenas se esforzaron por mantener su independencia como en la resistencia de los pueblos del norte a la invasión incásica,

\footnotetext{
10 Debido a que los textos escolares empiezan a hablar de Independencia del Ecuador desde los acontecimientos ocurridos en Quito a partir de 1809, debemos informar que somos conscientes de que la consolidación del Ecuador como República Independiente no se produce hasta 1830, momento en el que los líderes del Distrito Sur decidieron separarse de la Gran Colombia y fundar un Estado Libre e Independiente. AYALA MORA, Enrique. Historia del Ecuador II. Época Republicana. Quito: Corporación Editora Nacional, 2015, p. 33.

${ }^{11}$ Los textos escolares analizados pueden consultarse al final del trabajo.

12 BRUÑO, G. M. Compendio de la Historia del Ecuador. Ecuador: Hermanos de las Escuelas Cristianas, 1915; BRUÑO, G. M. Resúmenes de la Historia del Ecuador. Ecuador: Hermanos de las Escuelas Cristianas, 1916.

${ }^{13}$ BRUÑO, G. M. Compendio de la Historia del Ecuador... Op. cit., p. 51.

${ }^{14}$ CANO, F. A. Nociones elementales de Historia del Ecuador. Ecuador: Prensa Católica, 1920.

15 Ibídem, pp. 32-34.

16 UZCÁTEGUI García, Emilio. Historia del Ecuador. Texto para la Enseñanza de Historia Patria. Quito: Editorial Bolívar, 1929.
} 
o en la lucha entre Atahualpa y Huáscar. Lo interesante de esta información es que el autor no presenta a los indígenas como protagonistas de la Independencia, habla de ellos en pasado y como si se tratara de un grupo separado del conjunto del país ${ }^{17}$. Asimismo, y al igual que Bruño, realiza una alusión sobre la participación del pueblo en la Independencia desempeñando el papel de masa, de tumulto en los conflictos violentos: afirma, por ejemplo, que en el 2 de agosto de 1810 el pueblo decidió asaltar el presidio y los cuarteles para liberar a los presos después de los acontecimientos ocurridos el 10 de agosto de $1809^{18}$.

Llegados a este punto, se puede apreciar que las comunidades indígenas, negras, zambas, mulatas y mestizas, no forman parte del desarrollo político, económico y social, ya que tras los acontecimientos ocurridos en el denominado Primer Grito de Independencia se convocó un Cabildo Abierto donde dichas comunidades no participaron. En cambio, sí contó con la presencia del Municipio de la ciudad (Quito), el Cabildo eclesiástico, abogados, rectores de universidades, etc., es decir, grupos de poder y profesiones ocupadas en su mayoría por criollos y peninsulares $^{19}$.

Por su parte Moscoso 20 , dedica varías páginas de su obra para realizar una biografía de los próceres criollos de la Independencia, estos son: Francisco Miranda, Antonio Nariño, Eugenio Espejo ${ }^{21}$ y Antonio Ante. Este último es definido como el verdadero promotor de la Independencia, el discípulo más aprovechado de Espejo. La perspectiva que ofrecen Bruño, Cano y Uzcátegui, es que todos los criollos son partidarios del bando patriota que luchaba por lograr la emancipación. Sin embargo, Moscoso habla de criollos partidarios del bando realista como el quiteño Juan José Guerrero y Matheu, Conde de Selva Florida, Manuela Sáenz de Vergara (hermana de Manuela Sáenz la patriota) quien participó en una campaña dirigida por el coronel español Sámano contra los patriotas, y el coronel Nicolás López, criollo realista que participó en la Independencia de Guayaquil22. Al mismo tiempo, el autor, otorga una sección exclusiva de su libro para conocer a los próceres quiteños; todos ellos criollos (tabla 1).

\footnotetext{
17 Ibídem, pp. 11-46.

18 BRUÑN, G. M. Compendio de la Historia del Ecuador... Op. cit., p. 52.

19 UZCÁTEGUI García, Emilio. Historia del Ecuador... Op. cit., pp. 20-24.

20 MOSCOSO, Leonardo. Lecciones Elementales de la Historia General del Ecuador. Quito: J. Roberto Cruz, 1934.

21 Eugenio Espejo es definido por Uzcátegui como criollo.

22 MOSCOSO, Leonardo. Lecciones Elementales... Op. cit., pp. 61-80.
} 
Víctor H. SILVA GUIJARRO. ¿Guerra anticolonial o guerra civil? Análisis historiográfico sobre el protagonismo étnico en la independencia del Ecuador según los textos escolares de Historia (19152015).

\begin{tabular}{|c|c|c|}
\hline \multicolumn{3}{|c|}{ PRÓCERES } \\
\hline $\begin{array}{l}\text { Dirección } \\
\text { política }\end{array}$ & $\begin{array}{l}\text { Juan Pío Montúfar (Marqués de Selva-Alegre) } \\
\text { Pedro Montúfar } \\
\text { Coronel Carlos Montúfar } \\
\text { Jacinto Carrión Sánchez de Orellana (Marqués } \\
\text { de Solanda y Villaorellana) } \\
\text { Mariano Flores (Marqués de Miraflores) }\end{array}$ & $\begin{array}{l}\text { Manuel Matheu y } \\
\text { Herrera } \\
\text { Manuel Larrea } \\
\text { Guillermo Valdivieso } \\
\text { Joaquín Sánchez de } \\
\text { Orellana } \\
\text { Antonio León Carcelén } \\
\text { Ignacio León Carcelén } \\
\text { Juan de Dios Morales } \\
\text { Manuel Quiroga }\end{array}$ \\
\hline Clero & $\begin{array}{l}\text { Obispo Cuero y Caicedo } \\
\text { Miguel A. Rodríguez } \\
\text { Manuel J. Caicedo } \\
\text { Riofrío sacerdote de Pintac }\end{array}$ & $\begin{array}{l}\text { Castelo sacerdote de } \\
\text { Sangolquí } \\
\text { Correa sacerdote de } \\
\text { San Roque } \\
\text { Prudencio Vásconez }\end{array}$ \\
\hline Militares & $\begin{array}{l}\text { Coronel Juan de Salinas } \\
\text { Comandante Manuel Zaldumbide } \\
\text { Manuel Zambrano } \\
\text { Pablo Arenas }\end{array}$ & $\begin{array}{l}\text { Vicente Álvarez } \\
\text { Nicolás de la Peña } \\
\text { Javier Montúfar } \\
\text { José Larrea }\end{array}$ \\
\hline
\end{tabular}

Tabla 1: Próceres quiteños de la Independencia. Fuente: Elaboración propia a partir de Moscoso, 1934.

Tal y como se ha podido apreciar en este apartado, los textos escolares en su explicación de la Independencia certifican que este fue un acontecimiento histórico, político, social y económico que tuvo como principales protagonistas a criollos y peninsulares. Para corroborar esta afirmación, hemos realizado un recuento del número de veces que los distintos grupos étnicos son partícipes del proceso independentista según los textos escolares publicados entre 1915 y 1930. Los resultados obtenidos (gráfica 1) están marcados por el predominio de los criollos y peninsulares sobre mestizos, indígenas y zambos ${ }^{23}$. Mulatos y negros no son mencionados.

${ }^{23}$ Moscoso habla de la participación de zambos peruanos en la vanguardia liderada por el coronel español Manuel Arrendondo. MOSCOSO, Leonardo. Lecciones Elementales... Op. cit., p. 65. 


\section{GRUPOS ÉTNICOS EN LA INDEPENDENCIA 1915-1930}

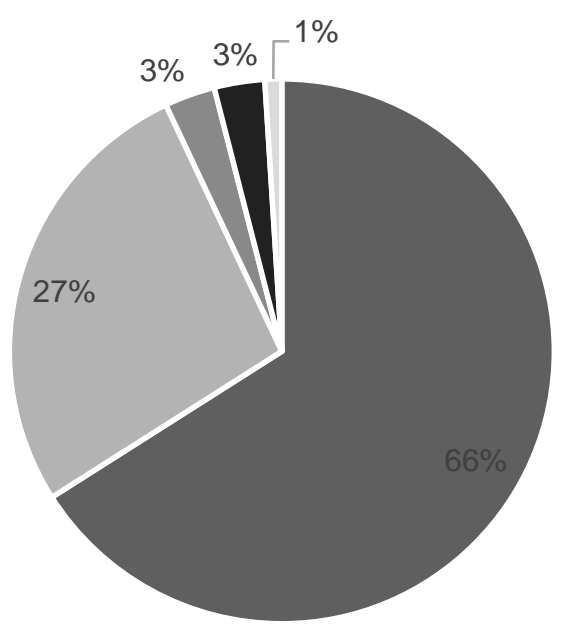

- Criollos - Peninsulares " Mestizos - Europeos "Indígenas

Gráfica 1: Análisis del protagonismo étnico en la Independencia del Ecuador (1915-1930) ${ }^{24}$. Fuente: Elaboración propia a partir de Bruño, Cano, Uzcátegui y Moscoso25.

\subsection{Los pardos y el ascenso del protagonismo popular (pueblo) (1940- 1990)}

Debido a la gran cantidad de datos que aportan los autores que publican sus obras entre 1940 y 1990, analizaremos con más detalle la explicación realizada por los textos escolares de los acontecimientos ocurridos en la Independencia con el fin de conocer a los protagonistas del mismo.

Las explicaciones elaboradas por los textos escolares certifican que el levantamiento quiteño ha estado copado exclusivamente por criollos y peninsulares. Por esta razón, tanto en las dos obras de Cevallos $^{26}$ como en la de Carrillo ${ }^{27}$ se aprecia que los principales protagonistas de la primera reunión celebrada en diciembre de 1808 para preparar el golpe contra los peninsulares ${ }^{28}$ fueron los integrantes de la escuela ideológica que había formado Eugenio Espejo ${ }^{29}$. Algunos de estos integrantes fueron los criollos Morales, Quiroga, Arenas, entre otros. Cabe recordar que esta reunión fracasó, los organizadores fueron apresados y después

\footnotetext{
24 Debido al gran protagonismo de los peninsulares se los ha separado del bloque correspondiente a europeos.

${ }^{25}$ BRUÑO, G. M. Compendio de la Historia del Ecuador... Op. cit.; BRUÑO, G. M. Resúmenes de la Historia del Ecuador... Op. cit.; CANO, F. A. Nociones elementales de Historia del Ecuador... Op. cit.; UZCÁTEGUI García, Emilio. Historia del Ecuador... Op. cit.; MOSCOSO, Leonardo. Lecciones Elementales... Op. cit.

${ }^{26}$ CEVAlLOS GARCÍA, Gabriel. Historia del Ecuador 5ํㅡㄴ. Curso. Ciclo Diversificado. Cuenca: Don Bosco, 1972; CEVALLOS GARCÍA, Gabriel. Historia del Ecuador 5ํ Curso. Colección LNS. Cuenca: Don Bosco, 1978.

${ }^{27}$ CARRILLO DE LANDÁZURI, Rogelia. El libro del Escolar Ecuatoriano 6. Quito: Edimpres, 1997.

28 Ibídem, p. 346.

${ }^{29}$ CEVALLOS GARCÍA, Gabriel. Historia del Ecuador 5ํㅡㄴ. Curso. Colección LNS... Op. cit., p. 202.
} 
liberados por la falta de pruebas. Cevallos afirma que los criollos republicanos aprovecharon la celebración de un "sarao" el 9 de agosto de 1809 en la vivienda de Manuela Cañizares para formar una nueva Junta de Gobierno y promulgar la primera "Acta Política de Emancipación", a partir de la cual se buscaba deponer a las autoridades españolas del poder. Este autor certifica que los protagonistas y representantes del nuevo Gobierno de Quito fueron todos criollos (tabla 2) ${ }^{30}$.

\begin{tabular}{|l|l|l|}
\hline \multicolumn{2}{|c|}{ PROTAGONISTAS DE LA PRIMERA JUNTA DE QUITO } \\
\hline \multirow{3}{*}{ Élite criolla votante } & Juan de Dios Morales & Mariano Villalobos \\
& Manuel Rodríguez de Quiroga & Juan Coello \\
& Juan Pablo Arenas & Miguel Donoso \\
& Francisco Romero & Antonio Ante \\
& Luis Saa & Feliciano Checa \\
& Manuel Cevallos & José Cañizares \\
& Joaquín Barrera & Carlos Larrea \\
& Pedro Veintimilla & Juan Antonio \\
& Antonio Castelo & Ribadeneira \\
& Marqués de Miraflores & Marqués de Villaorellana \\
& Manuel de Larrea & Manuel Zambrano \\
& Nicolás Vélez & Manuel Matheu \\
& Antonio Sierra & Ramón Egas \\
& Gregorio Flor & Vicente Paredes \\
& Manuel Cevallos & Luis Vargas \\
\hline Presidente de la Junta & Marqués de Selva Alegre Juan Pio Montufar \\
\hline Ministros y & Ministro de Negocios públicos y de & Jefe de Falange: Juan \\
secretarios de Estado & Guerra: Juan de Dios Morales & Salinas \\
& Ministro de Gracia y Justicia: Manuel & Auditor de Guerra: Pablo \\
& Quiroga & Arenas \\
& \multicolumn{2}{|l|}{ Ministro de Hacienda: } \\
\cline { 2 - 2 } & Obispo Cuero y Caicedo & Suan de Larrea \\
\hline Clero & Sacerdote José Correa \\
\hline
\end{tabular}

Tabla 2:. Actores principales en la articulación de la primera Junta de Gobierno de Quito y en la emisión de la "Acta Política de Emancipación". Fuente: Elaboración propia a partir de Cevallos ${ }^{31}$.

Carrillo ${ }^{32}$ y Núñez $z^{33}$ afirman que, pese a su triunfo inicial, esta Junta fracasó porque según sus autores el Primer Grito de Independencia fue una conspiración que no se basó en el pueblo ${ }^{34}$ sino en los intereses de los jefes criollos ${ }^{35}$. La élite criolla para encontrar una solución a este problema emprendió en las primeras actividades de la Junta una serie de reformas para atraer al pueblo. Después de los fracasos de la Junta llegó la reacción monárquica que provocó el fin de este organismo político y el retorno del Conde Ruiz de Castilla. El grupo realista (tabla 3) estuvo compuesto no solo por peninsulares, sino también por criollos que apoyaban

30 CEVALLOS GARCíA, Gabriel. Historia del Ecuador 5ํㅡㄴ. Ciclo Diversificado... Op. cit., pp. 228230.

31 CeVAllos García, Gabriel. Historia del Ecuador 5 Curso. Ciclo Diversificado... Op. cit.

32 CARRILLO DE LANDÁZURI, Rogelia. El libro del Escolar Ecuatoriano 6... Op. cit.

${ }^{33}$ NÚÑEZ SÁNCHEZ, Jorge. Historia del Ecuador. Quito: Santillana, 1997.

${ }^{34}$ CARRILLO DE LANDÁZURI, Rogelia. El libro del Escolar Ecuatoriano 6... Op. cit., p. 346.

${ }^{35}$ NÚÑ̃EZ SÁNCHEZ, Jorge. Historia del Ecuador... Op. cit., p. 9. 
su causa como Tomás Arechaga, Ministro de Justicia de la Junta que conspiró desde dentro en favor de los realistas ${ }^{36}$.

\begin{tabular}{|l|l|l|}
\hline \multicolumn{2}{|c|}{ BANDO REALISTA } \\
\hline Peninsulares & Antonio Amar y Borbón Virrey de & Fuertes Amar \\
realistas & Bogotá & Gregorio Angulo \\
& Abascal Virrey de Lima & Comandante Drupe \\
& Cucalón Gobernador de Guayaquil & Nieto Polo \\
& Aymerich Gobernador de Cuenca & Capitán Fernando \\
& General Arredondo & Bassantes \\
& Joaquín Villaespesa & Comandante Juan Alderete \\
\hline Criollos realistas & Obispo Quintián Ponte & Tomás Arechaga \\
& Juan José Guerrero & \\
\hline
\end{tabular}

Tabla 3: Protagonistas de la reacción monárquica contra la primera Junta. Fuente: Elaboración propia a partir de Cevallos ${ }^{37}$.

Consolidado nuevamente en el poder, Ruiz de Castilla ordenó el arresto de todos los participantes del 10 de agosto ${ }^{38}$. Según Carrillo ${ }^{39}$, los presos se convirtieron en un símbolo de opresión ${ }^{40}$ y a partir de este momento fue cuando el pueblo quiteño se involucró con la causa criolla ${ }^{41}$. No obstante, todo terminó, según Cevallos ${ }^{42}$, en la masacre del 2 de agosto. Durante este acontecimiento, los principales articuladores del Primer Grito de Independencia fueron asesinados y es aquí donde se atestigua la participación de un contingente de soldados zambos limeños a favor de la causa realista, del mismo modo que mestizos partidarios de los republicanos criollos ${ }^{43}$. Para intentar solucionar los problemas, el Consejo de Regencia envió como comisionado regio a Carlos Montúfar, quien llegó a Quito en septiembre de 1810 y formó una Segunda Junta Soberana que trajo consigo nuevos enfrentamientos entre peninsulares y criollos, también entre criollos radicales y moderados (sanchistas y montufaristas) y la articulación de una Constitución dónde los únicos protagonistas siguieron siendo solo peninsulares y criollos. Esta nueva Junta fracasó y se produjo la victoria realista (tabla 4$)^{44}$.

\footnotetext{
${ }^{36}$ CEVALLOS GARCÍA, Gabriel. Historia del Ecuador 5º Curso. Ciclo Diversificado... Op. cit., pp. 232238.

${ }^{37}$ CEVAlLOS GARCÍA, Gabriel. Historia del Ecuador 50 Curso. Ciclo Diversificado... Op. cit.

38 CEVALLOS GARCíA, Gabriel. Historia del Ecuador 5 Curso... Op. cit., p. 209.

39 CARRILLO DE LANDÁZURI, Rogelia. El libro del Escolar Ecuatoriano 6... Op. cit.

40 Ibídem, p. 348.

${ }^{41}$ CEVALLOS GARCÍA, Gabriel. Historia del Ecuador 5ํㅡㄴ. Curso. Ciclo Diversificado... Op. cit., pp. 240241.

${ }^{42}$ CEVALLOS GARCÍA, Gabriel. Historia del Ecuador 5ํㅡㄴ Curso. Colección LNS... Op. cit.

${ }^{43}$ CEVALLOS GARCÍA, Gabriel. Historia del Ecuador 5ํㅡㄴ. Curso... Op. cit., pp. 210-212.

${ }^{44}$ CEVALLOS GARCÍA, Gabriel. Historia del Ecuador 5ํㅡㄴ. Curso. Ciclo Diversificado... Op. cit., pp. 239252.
} 
Víctor H. SILVA GUIJARRO. ¿Guerra anticolonial o guerra civil? Análisis historiográfico sobre el protagonismo étnico en la independencia del Ecuador según los textos escolares de Historia (19152015).

\begin{tabular}{|c|c|c|}
\hline \multicolumn{3}{|c|}{ PROTAGONISTAS DE LA II JUNTA Y DE LA VICTORIA REALISTA } \\
\hline Criollos patriotas & $\begin{array}{l}\text { Carlos Montúfar } \\
\text { Obispo Cuero y } \\
\text { Caicedo } \\
\text { José Manuel Caicedo } \\
\text { Joaquín Sánchez de } \\
\text { Orellana } \\
\text { Joaquín Pérez Anda } \\
\text { Juan de Larrea } \\
\text { Mariano Merizalde } \\
\text { Juan Donoso } \\
\text { Pedro Montufar } \\
\text { Manuel Aguilar } \\
\text { Carlos Larrea } \\
\text { Fray Estevan Riera } \\
\text { José Barba } \\
\text { Antonio Ante }\end{array}$ & $\begin{array}{l}\text { Francisco Javier Salazar Mariano } \\
\text { Guillermo Valdivieso } \\
\text { Pedro Jacinto de Escobar } \\
\text { Manuel Zambrano } \\
\text { Francisco Rodríguez Soto } \\
\text { Manuel de Larrea } \\
\text { Manuel Matheu y Herrera } \\
\text { Francisco Calderón } \\
\text { Rosa Montúfar y Larrea } \\
\text { Feliciano Checa } \\
\text { Manuel Aguilar } \\
\text { Bernardo León } \\
\text { Jacinto Sánchez }\end{array}$ \\
\hline Europeos patriotas & Oficial Gullon & Capitán Brow \\
\hline $\begin{array}{l}\text { Peninsulares } \\
\text { realistas }\end{array}$ & $\begin{array}{l}\text { Ruiz de Castilla } \\
\text { Abascal } \\
\text { Aymerich } \\
\text { Miguel Tacón } \\
\text { Mariscal Toribio Montes } \\
\text { Juan Sámano } \\
\text { Juan de la Cruz } \\
\text { Murgeón }\end{array}$ & $\begin{array}{l}\text { Brigadier Joaquín Molina de Zuleta } \\
\text { Arredondo Gobernador de Pasto } \\
\text { Benito Bennet } \\
\text { General Juan Ramírez } \\
\text { Pablo Morillo }\end{array}$ \\
\hline Criollos realistas & $\begin{array}{l}\text { Quintián Ponte } \\
\text { Pedro Calixto } \\
\text { Pedro Pérez Muñoz }\end{array}$ & $\begin{array}{l}\text { Nicolás Calixto } \\
\text { María Calixto Borja }\end{array}$ \\
\hline
\end{tabular}

Tabla 4: Protagonistas de la segunda Junta de Gobierno y del nuevo triunfo conseguido por el bando realista en Quito. Fuente: Elaboración propia a partir de Cevallos, Carrillo y Núñez ${ }^{45}$.

En lo que respecta a la Independencia guayaquileña, Carrillo46 plantea que la etapa decisiva de la Independencia del Ecuador empezó en Guayaquil|47. De esta manera, para conocer el protagonismo de los distintos grupos étnicos estudiaremos este acontecimiento en dos etapas; la primera corresponderá a la Independencia de Guayaquil y la segunda a la Independencia de la Sierra.

En esta primera etapa, según Cevallos ${ }^{48}$, los principales alentadores del independentismo guayaquileño fueron los militares venezolanos Febres Cordero, Letamendi y Urdaneta ${ }^{49}$. Núñez $z^{50}$ afirma que estos militares se unieron a la logia masónica llamada "La fragua de Vulcano", cuyo objetivo era la conspiración

45 CEVAllos GARCÍA, Gabriel. Historia del Ecuador 5ํㅡ. Curso. Ciclo Diversificado... Op. cit.; CARRILLO DE LANDÁZURI, Rogelia. El libro del Escolar Ecuatoriano 6... Op. cit NÚÑEZ SÁNCHEZ, Jorge. Historia del Ecuador... Op. cit.

${ }^{46}$ CARRILLO DE LANDÁZURI, Rogelia. El libro del Escolar Ecuatoriano 6... Op. cit.

47 Ibídem, p. 350.

${ }^{48}$ CEVALLOS GARCÍA, Gabriel. Historia del Ecuador 5ํㅡㄴ. Curso. Ciclo Diversificado... Op. cit.

49 lbídem, p. 258.

50 NÚÑEZ SÁNCHEZ, Jorge. Historia del Ecuador... Op. cit. 
anticolonial $^{51}$. Algunos de los miembros de este grupo fueron: Francisco Elizalde, José María Villamil, Lorenzo Garaicoa, José Vallejo, Vicente Ramón Roca, entre otros $^{52}$. El 9 de octubre de 1820 se consumó la Independencia de Guayaquil ${ }^{53}$ y el poder civil pasó a manos del criollo José Joaquín de Olmedo, quien convocó una reunión popular para articular una Junta Gubernativa provisional. Posteriormente se redactó una Constitución y se consolidó una Junta Suprema donde los únicos protagonistas fueron los criollos guayaquileños y venezolanos (tabla 5) ${ }^{54}$.

\begin{tabular}{|c|c|c|}
\hline \multicolumn{3}{|c|}{ JUNTA SUPREMA DE GUAYAQUIL } \\
\hline Dirección política & $\begin{array}{l}\text { José de Antepara } \\
\text { José María Villamil } \\
\text { Francisco de Paula Lavayen } \\
\text { José Vallejo } \\
\text { José Joaquín de Olmedo } \\
\text { Luis Fernando de Vivero } \\
\text { Antonio Elizalde } \\
\text { José Rivas } \\
\text { José Correa }\end{array}$ & $\begin{array}{l}\text { Juan Francisco Elizalde } \\
\text { Lorenzo Garaicoa } \\
\text { Vicente Ramón Roca } \\
\text { Jacinto Bejarano } \\
\text { Francisco Marcos } \\
\text { Francisco M. Roca } \\
\text { Fajardo } \\
\text { Rafael Jimena }\end{array}$ \\
\hline Dirección militar & $\begin{array}{l}\text { León Febres Cordero (Venezuela) } \\
\text { Joaquín Escobedo. }\end{array}$ & $\begin{array}{l}\text { Miguel Letamendi (Venezuela) } \\
\text { Luis Urdaneta (Venezuela) }\end{array}$ \\
\hline
\end{tabular}

Tabla 5: Próceres criollos guayaquileños y venezolanos de la Independencia de Guayaquil. Fuente: Elaboración propia a partir de Cevallos, Carrillo y Núñez; $1997^{55}$.

La segunda etapa de este proceso se abre con el nuevo objetivo de los patriotas guayaquileños: la Independencia de la Sierra ${ }^{56}$. Cevallos ${ }^{57}$ afirma que en esta labor desempeñó un papel relevante el criollo Luis Urdaneta, quien por medio de sus proclamas influyó en el proceso de Independencia de Ambato, Latacunga y Cuenca con un protagonismo total de criollos y peninsulares (tabla 6) ${ }^{58}$.

\footnotetext{
51 Ibídem, p. 10.

52 CEVAlLOS GARCÍA, Gabriel. Historia del Ecuador 5 Curso. Ciclo Diversificado... Op. cit., p. 258.

${ }^{53}$ CEVALLOS GARCÍA, Gabriel. Historia del Ecuador 5 Curso... Op. cit., p. 220.

54 CEVALLOS GARCíA, Gabriel. Historia del Ecuador 5ํㅡㄴ. Curso. Ciclo Diversificado... Op. cit., pp. 259260.

55 CEVAllos GARCÍA, Gabriel. Historia del Ecuador 5 Curso. Ciclo Diversificado... Op. cit.; CARRILLO DE LANDÁZURI, Rogelia. El libro del Escolar Ecuatoriano 6... Op. cit.; NÚÑ̃EZ SÁNCHEZ, Jorge. Historia del Ecuador... Op. cit.

${ }^{56}$ CARRILLO DE LANDÁZURI, Rogelia. El libro del Escolar Ecuatoriano 6... Op. cit., p. 351.

${ }^{57}$ CEVALLOS GARCÍA, Gabriel. Historia del Ecuador 50 Curso. Ciclo Diversificado... Op. cit.

${ }^{58}$ CEVALLOS GARCÍA, Gabriel. Historia del Ecuador 5ํㅡㄴ Curso. Ciclo Diversificado... Op. cit., pp. 261262.
} 
Víctor H. SILVA GUIJARRO. ¿Guerra anticolonial o guerra civil? Análisis historiográfico sobre el protagonismo étnico en la independencia del Ecuador según los textos escolares de Historia (19152015).

\begin{tabular}{|l|l|l|}
\hline \multicolumn{3}{|c|}{ INDEPENDENCIA DE CUENCA } \\
\hline Criollos patriotas & Tomás Ordóñez & Felipe Serrano \\
& León de la Piedra & Vicente Toledo \\
& Joaquín Salazar y Lozano & Joaquín Astudillo \\
& Hidalgo de Cisneros & Jerónimo Illescas \\
& Pedro Serrano & Zenón de San Martín \\
& José María Vázquez de Noboa \\
& Járroco Maestro Javier de Loyola. & \\
\hline Peninsulares realistas & Melchor Aymerich & Antonio García y Tréllez \\
\hline Criollos realistas & Obispo Quintián Ponte & \multicolumn{2}{l}{} \\
\hline
\end{tabular}

Tabla 6: Criollos y peninsulares enfrentados en la lucha por la liberación de Cuenca. Fuente: Elaboración propia a partir de Cevallos ${ }^{59}$.

Cevallos ${ }^{60}$ informa que el proyecto para liberar la Sierra por parte de los criollos guayaquileños y venezolanos fracasó debido a las derrotas sufridas ante el ejército español al mando de los generales Francisco González y Melchor Aymerich ${ }^{61}$. Es en este momento cuando Bolívar y San Martín entraron en escena enviando soldados para apoyar la causa guayaquileña y acabar con el dominio español. Uno de estos fue el criollo venezolano Antonio José de Sucre, quien según Cevallos ${ }^{62}$ fue enviado por Bolívar para liderar al ejército republicano (tabla 7) ${ }^{63}$.

\begin{tabular}{|l|l|l|}
\hline \multicolumn{3}{|c|}{ BANDO REPUBLICANO } \\
\hline Criollos & $\begin{array}{l}\text { Simón Bolívar } \\
\text { General Sucre } \\
\text { Coronel Cestaris, } \\
\text { Coronel Luis Urdaneta }\end{array}$ & $\begin{array}{l}\text { José de San Martín } \\
\text { Coronel Guido } \\
\text { Araujo } \\
\text { General Santa Cruz. }\end{array}$ \\
\hline Europeos & $\begin{array}{l}\text { General Mires, } \\
\text { Coronel Illingworth }\end{array}$ & $\begin{array}{l}\text { Almirante Lord Cochrane } \\
\text { Lavalle }\end{array}$ \\
\hline \multicolumn{2}{|c|}{ BANDO REALISTA } \\
\hline Peninsulares & $\begin{array}{l}\text { General Aymerich } \\
\text { General Francisco González } \\
\text { General Pablo Morillo }\end{array}$ & $\begin{array}{l}\text { General Mourgeon } \\
\text { General Tolrá }\end{array}$ \\
\hline Criollos & Coronel Nicolás López \\
\hline
\end{tabular}

Tabla 7: Protagonistas del bando republicano y realista en los últimos enfrentamientos antes de la proclamación definitiva de Independencia. Fuente: Elaboración propia a partir de Cevallos ${ }^{64}$.

Núñez $z^{65}$ indica que Sucre asumió el liderazgo de un contingente militar compuesto por quiteños, colombianos, venezolanos, peruanos, argentinos e ingleses. Después de numerosas batallas que se saldaron con derrotas y victorias para los dos bandos, la guerra terminó con la Batalla del Pichincha el 24 de mayo de 1822 saliendo

\footnotetext{
${ }^{59}$ CEVALLOS GARCÍA, Gabriel. Historia del Ecuador 5ํㅡㄴ. Curso. Ciclo Diversificado... Op. cit.

60 lbídem.

61 Ibídem, pp. 261-262.

62 CEVALLOS GARCíA, Gabriel. Historia del Ecuador 5 Curso. Colección LNS... Op. cit.

${ }^{63}$ CEVALLOS GARCÍA, Gabriel. Historia del Ecuador 5ํㅡㄴ. Curso... Op. cit., pp. 224-225.

64 CeVAllos GARCÍA, Gabriel. Historia del Ecuador 5ำ Curso. Ciclo Diversificado... Op. cit.; CEVALLOS GARCÍA, Gabriel. Historia del Ecuador 5ํㅡ. Curso. Colección LNS... Op. cit.

${ }^{65}$ NÚÑEZ SÁNCHEZ, Jorge. Historia del Ecuador... Op. cit.
} 
victorioso el bando republicano66. Con todo lo dicho, se aprecia que en las obras de estos autores (Cevallos, Carrillo, Núñez) los únicos protagonistas de la Independencia de Guayaquil fueron exclusivamente criollos y peninsulares ya que en ninguno de estos textos escolares hay una mención referente a la participación de indígenas, negros o mulatos.

Al responder a esta pregunta y realizar el recuento de los protagonistas en este acontecimiento (gráfica 2), se puede apreciar que, tanto en los acontecimientos ocurridos en Quito como en Guayaquil, lo más característico es el poco protagonismo de indígenas, negros, mulatos, zambos y pardos. Sobre esta situación, Cevallos y Carrillo no se pronuncian al respecto, en cambio Núñez afirma tajantemente que la Independencia fue un proceso que tuvo como principales actores a los criollos y peninsulares; asimismo, informa que el escaso protagonismo de indígenas, negros, mulatos, etc., se debe a que estos no se identificaron con la Independencia pues consideraban que fue un proyecto elaborado exclusivamente para criollos ${ }^{67}$. No obstante, y en comparación con el análisis anterior, se encuentra la participación (aunque mínima) de un nuevo grupo que no ha sido mencionado hasta ahora, los pardos. Otro dato a destacar es el ascendente protagonismo que adquiere la reacción popular. Los europeos y los mestizos se mantienen con los mismos valores del primer periodo cronológico, no así los peninsulares quienes aumentan su participación mientras que los criollos experimentan cierta pérdida protagónica, aunque mínima, puesto que siguen siendo el grupo dominante.

\footnotetext{
66 lbídem, p. 10.
}

67 Ibídem. 


\section{GRUPOS ÉTNICOS EN LA INDEPENDENCIA 1940-1990}

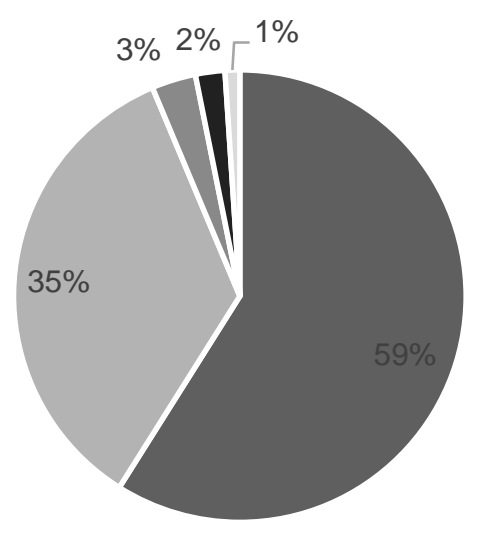

- Criollos

- Peninsulares

- Mestizos

- Europeos

Indígenas, mulatos, negros, zambos, pardos = Pueblo

Gráfica 2: Análisis del protagonismo étnico en la Independencia del Ecuador (1940-1990) ${ }^{68}$. Fuente: Elaboración propia a partir de Cevallos, Carrillo y Núñez ${ }^{69}$.

\subsection{Los cholos y la idea de la Independencia como un objetivo común para todos los grupos étnicos (2000-2015)}

En su obra publicada en 2001 Navas ratifica que tanto en la primera reunión de los patriotas, como en la consolidación de la Primera Junta de Gobierno quiteño y la posterior articulación de la "Primera Acta Política de Emancipación", los protagonistas de los acontecimientos siguieron siendo los mismos. Además de todos los actores criollos mencionados por Cevallos ${ }^{70}$ (véase tabla 2), Navas presenta a nuevos patriotas criollos como José Padilla, Juan Ante, Antonio Pineda, Toribio Ortega y José Bosmediano. A partir del 2 de agosto, como dijimos anteriormente, el pueblo de Quito va adquiriendo un ascendente protagonismo de modo que, según este autor, los quiteños organizaron un levantamiento popular cuyo objetivo era liberar a quienes pretendían darles la libertad. Para este cometido se organizó un grupo de cincuenta cholos dirigidos por cuatro quiteños, José Jerez, Pereira, Silva y Rodríguez. Como ya mencionamos anteriormente, todo acabó en una masacre, tanto el pueblo como los criollos fueron asesinados por los realistas peninsulares y los zambos limeños dirigidos por el teniente coronel Manuel Arredondo. Otro dato novedoso es la breve mención que hace el autor sobre la esclava negra de Quiroga que también fue asesinada junto a este el 2 de agosto. A raíz de los acontecimientos

\footnotetext{
${ }^{68}$ Los niveles de participación de indígenas, negros, mulatos, zambos y pardos son tan bajos que hemos decidido juntarlos para que puedan figurar en el recuento de los protagonistas de la Independencia.

69 CEVAllos GaRcía, Gabriel. Historia del Ecuador 5 Curso. Ciclo Diversificado... Op. cit.; CEVALLOS GARCÍA, Gabriel. Historia del Ecuador 5ํㅡㄴ Curso. Colección LNS... Op. cit.; CARRILLO DE LANDÁZURI, Rogelia. El libro del Escolar Ecuatoriano 6... Op. cit.; NÚÑEZ SÁNCHEZ, Jorge. Historia del Ecuador... Op. cit.

70 CEVALLOS GARCíA, Gabriel. Historia del Ecuador 5ํㅡㄴ. Curso. Ciclo Diversificado... Op. cit.
} 
producidos por la llegada de Carlos Montúfar, el pueblo también fue partícipe de los nuevos enfrentamientos donde los criollos contaron con el apoyo de mestizos y por primera vez de indígenas ${ }^{71}$.

En la proclamación de la Independencia de Guayaquil no se han encontrado cambios significativos, los principales referentes siguieron siendo los criollos venezolanos (Febres Cordero, Urdaneta, Letamendi) y los criollos guayaquileños (Olmedo, Jimena, etc.). En este caso no hay mención alguna sobre el pueblo, pero Navas $^{72}$ sí presenta a otros miembros de la cúpula criolla como: Isidoro Viteri, Diego Noboa, Damián Nájera y a los peninsulares realistas Manuel Torres Valdivia y Joaquín Magallar. También aporta datos novedosos sobre los miembros del ejército que lideró el General Sucre en la Batalla del Pichincha, el cual estaba compuesto por soldados de varias nacionalidades europeas, así como por criollos venezolanos, argentinos, colombianos, bolivianos. Sobre el ejército realista el autor no aporta información detallada, simplemente menciona el momento en el que el General Aymerich capituló ante Sucre ${ }^{73}$.

Holguín ${ }^{74}$ en su estudio sobre la Independencia incorpora la situación colonial. Es por este motivo que en su obra se visibiliza un aumento del protagonismo de los grupos étnicos marginados, los cuales aparecen representados como los principales articuladores de los levantamientos populares durante el periodo colonial. Este texto escolar se desmarca de lo planteado hasta el momento por los anteriores autores, ya que Holguín otorga un protagonismo central durante la Independencia a los indígenas, negros y mestizos, no como grupo dirigente, sino como víctimas de todo el periodo colonial. Sobre lo ocurrido en Quito sigue la línea expuesta por Navas pero añadiendo un nuevo apunte; afirma que tras la crisis provocada por el 10 de agosto de 1809 y el 2 de agosto de 1810, las autoridades peninsulares organizaron una Asamblea de Notables, donde el protagonismo creciente del pueblo de Quito le permitió exigir el cumplimiento de ciertos aspectos como: la admisión del Comisionado Regio Montúfar, el abandono de las tropas limeñas de Arredondo y la organización de la guarnición de la ciudad con soldados pertenecientes a ella. En lo que respecta a la Independencia de Guayaquil, lo propuesto por este autor se mantiene en la línea de lo manifestado anteriormente y además presenta a los líderes criollos guayaquileños que firmaron el "Acta de Independencia" (tabla 8). Holguín termina su capítulo afirmando que los únicos líderes y patriotas que hicieron realidad la creación de un nuevo escenario político fueron los criollos pertenecientes a las familias distinguidas ${ }^{75}$.

\footnotetext{
71 NAVAS JIMÉNEZ, Mario. Estudios Sociales 9. Quito: Quebecor World Bogotá, 2001, pp. 122-126.

72 NAVAS JIMÉNEZ, Mario. Estudios Sociales 9... Op. cit.

73 Ibídem, pp. 126-131.

74 HOLGUIN ARIAS, Rubén. Estudios Sociales 5. Quito: Holguín Ediciones, 2003.

75 Ibídem, pp. 66-80.
} 


\begin{tabular}{|l|l|l|}
\hline \multicolumn{3}{|c|}{ FIRMANTES DEL “ACTA DE INDEPENDENCIA DE GUAYAQUIL” } \\
\hline José Joaquín de Olmedo & Manuel de José Herrera & Gabriel García Gómez \\
\hline José Antonio Espantoso & Pedro Santander & José M. Maldonado \\
\hline José Ramón Menéndez & Francisco de Macos & José de Villamil \\
\hline
\end{tabular}

Tabla 8: Firmantes del "Acta de Independencia de Guayaquil”. Fuente: Elaboración propia a partir de Holguín ${ }^{76}$.

Muñoz ${ }^{77}$, consolida la idea de que los principales actores de la Independencia fueron los representantes de los grupos étnicos humillados y explotados, es decir los mestizos y los indígenas. Para el autor, el deseo de libertad surgió en estos porque fueron las víctimas del dominio español. Debido al ultraje y desprecio que sufrieron los mestizos al considerarlos como no aptos para desempeñar los cargos que ocupaban los peninsulares, el autor afirma que los precursores del sentimiento independentista fueron los mestizos con formación como Francisco Miranda, Antonio Nariño, Eugenio Espejo ${ }^{78}$ y José Mejía Lequerica. En esta obra, en un principio, el criollo queda relegado a un segundo plano por los mestizos; ejemplo de esto es que algunos de los próceres del independentismo que fueron catalogados por los anteriores autores como criollos, Muñoz se refiere a ellos como mestizos. Sin embargo, en los acontecimientos venideros, (Revolución de Quito, Independencia de Guayaquil, Batalla del Pichincha) en esta obra se certifica que los protagonistas siguieron siendo los mismos: criollos y peninsulares ${ }^{79}$.

La obra del Ministerio de Educación ${ }^{80}$ aporta nueva información referente a la Independencia de Cuenca, que no ha sido estudiada desde la obra de Cevallos, acontecimiento donde sus principales libertadores fueron criollos (véase tabla 6). Sobre la Batalla del Pichincha, en este texto escolar se afirma que el triunfo de los patriotas criollos fue posible gracias a los servicios prestados por los guías mestizos e indígenas quienes lideraron al ejército durante el ascenso al volcán Pichincha ${ }^{81}$.

Ayala Mora ${ }^{82}$, divide a los principales protagonistas de la Revolución de Quito; los criollos, en dos grupos: los criollos latifundistas poseedores de títulos de marqueses y condes y los criollos activistas, abogados, intelectuales, medianos terratenientes y sacerdotes. Estos últimos fueron los organizadores de la Junta. EI autor considera que, debido a la falta de convicción sobre su gobierno, los criollos marqueses y los criollos activistas no contaron con el apoyo del pueblo urbano ni de los indígenas porque estos se dieron cuenta de que ese gobierno criollo no les aportaba ningún beneficio. Por esto los criollos tuvieron que esperar al 2 de agosto para contar con el apoyo de los grupos populares. Para los acontecimientos ocurridos en Guayaquil y la posterior Batalla del Pichincha, presenta el mismo

\footnotetext{
76 HOLGUÍN ARIAS, Rubén. Estudios Sociales 5... Op. cit.

77 MUÑOZ, Hernán. Estudios Sociales. Quito: Prolipa, 2007.

78 Muñoz presenta a Eugenio Espejo como mestizo.

79 MUÑOZ, Hernán. Estudios Sociales... Op. cit., pp. 112-132.

80 Ministerio de Educación. Estudios Sociales 9. Pichincha: Gobierno de Pichincha, 2008.

${ }^{81}$ Ibídem, pp. 90-93.

82 AYALA MORA, Enrique. Estudios Sociales 6. Historia Del Ecuador I. Época Aborigen, Colonia e Independencia. Quito: Corporación Editora Nacional, 2010.
} 
planteamiento sobre el protagonismo de los distintos grupos étnicos, es decir los actores principales fueron los criollos. Además, añade que los grupos populares (artesanos, comerciantes, campesinos, etc.) fueron reacios en un principio a la rebelión anticolonial, pero después pasaron a formar parte de las tropas de guerra. Asimismo, Ayala Mora afirma que los pueblos indígenas no apoyaron a esta causa porque no les favorecía, e incluso hubo algunos grupos que apoyaron al ejército realista. Todo lo contrario, ocurrió con los afroamericanos, los cuales, según el autor, al entender que su participación en la guerra era una vía de liberación de la esclavitud y de ascenso social se alistaron al ejército patriótico ${ }^{83}$.

En el libro de De la Cruz y Ruano Gómez, aparecen alusiones breves sobre los protagonistas de este proceso ya que los autores se centran más en cuestiones ideológicas. Definen al criollo como abanderado de la lucha contra la liberación de España y hacen referencias a los principales líderes criollos como Bolívar, Santander, Artigas y San Martín ${ }^{84}$.

Como se puede apreciar en el cálculo de la participación de los diferentes grupos étnicos (gráfica 3), aparece en escena un nuevo grupo: los cholos. Debido a su poca relevancia en este acontecimiento, los hemos incluido dentro de los grupos étnicos que podríamos catalogarlos como actores secundarios (indígenas, negros, mulatos, etc.). En relación con los bloques anteriores, mulatos y zambos desaparecen. No obstante, es de destacar la gran relevancia que adquieren indígenas y negros, esto se debe al mayor protagonismo que les dan estos autores, pues consideran que la Independencia solo se pudo consolidar con el apoyo de todos los grupos étnicos. Asimismo, es relevante la pervivencia protagónica del pueblo, el cual ha pasado de tener una influencia casi nula en el primer periodo, a consolidarse tanto en el segundo como en el tercero. Sin embargo, pese al rescate de la acción popular en la Independencia por parte de los autores, este acontecimiento sigue copado por los grandes libertadores criollos como Sucre, Olmedo, Febres Cordero, entre otros. Los mestizos también han experimentado un ascenso en su participación; esto se ha producido debido a planteamientos como los de Muñoz quien otorga gran protagonismo a este grupo. Es destacada la pérdida de protagonismo de los peninsulares, la cual ha sido asumida por los mestizos puesto que es el porcentaje que más ha crecido. Finalmente, los europeos han aumentado su protagonismo y esto se debe a que los autores han tratado con mayor desarrollo la Batalla del Pichincha donde la participación de europeos fue relevante ya no solo en el bando realista, sino también en el patriota.

\footnotetext{
83 Ibídem, pp. 83-87.

${ }^{84}$ CRUZ, Katherine de la y RUANO GÓMEZ, Olver. Enigmas I. Historia y Ciencias Sociales. Guayaquil: Argo, 2015, p. 188.
} 


\section{GRUPOS ÉTNICOS EN LA INDEPENDENCIA 2000-2015}

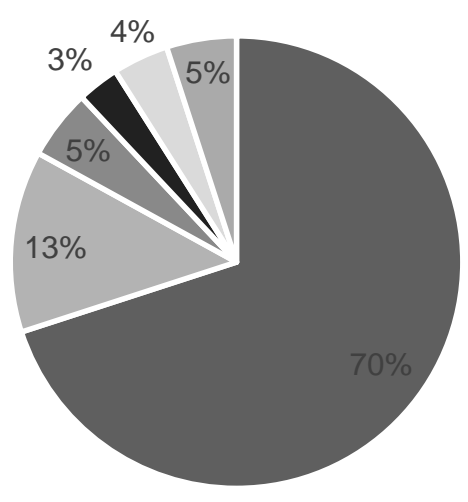

- Criollos

- Peninsulares

- Mestizos

- Europeos

- Indígenas, mulatos, negros, zambos, pardos = Pueblo

Gráfica 3: Análisis del protagonismo étnico en la Independencia del Ecuador (2000-2015). Fuente: Elaboración propia a partir de Holguín, Muñoz, Ministerio de Educación, Ayala Mora y De la Cruz y Ruano Gómez ${ }^{85}$.

\section{Los actores secundarios. Análisis sobre la participación de los grupos étnicos presentados como víctimas del dominio español}

En lo que respecta al escaso protagonismo otorgado por los textos escolares publicados en el siglo XX a los indígenas, mestizos, zambos, negros, mulatos, cholos, pardos, etc., en el desarrollo de la Independencia, se debe a que su participación se redujo casi exclusivamente a ser soldados de los ejércitos realistas e insurgentes. Dicha participación, según todos los autores del bloque correspondiente al siglo XXI (2000-2015), fue relevante para lograr la emancipación dirigida y organizada exclusivamente por las élites criollas.

Los avances realizados por las investigaciones historiográficas han puesto de manifiesto que indígenas, negros, zambos, pardos, etc., en el marco de su participación como soldados en la Guerra de Independencia, del mismo modo que fueron víctimas de abusos y contribuciones forzosas también tuvieron la capacidad de decidir (acorde a sus intereses) en qué bando alistarse ${ }^{86}$. A partir de esta afirmación se puede llegar a entender porqué los indígenas en un principio rechazaron apoyar a los insurgentes quiteños en 1809, para posteriormente involucrarse en la Batalla del Pichincha de 1822. Asimismo, se pueden comparar

85 HOLGUÍN ARIAS, Rubén. Estudios Sociales 5... Op. cit.; MUÑOZ, Hernán. Estudios Sociales... Op. cit.; Ministerio de Educación. Estudios Sociales 9... Op. cit.; AYALA MORA, Enrique. Estudios Sociales 6... Op. cit.; CRUZ, Katherine de la y RUANO GÓMEZ, Olver. Enigmas I... Op. cit.

${ }^{86}$ BERNAL RUIZ, Graciela. Sociedad y guerra: actitudes ante la insurgencia en San Luis Potosí, 1810-1821. En: ÁLVAREZ CUARTERO, Izaskun y SÁNCHEZ GÓMEZ, Julio (eds.). Visiones y revisiones de la Independencia de América. México, Centroamérica y Haití. Salamanca: Ediciones Universidad de Salamanca, 2005, pp. 157-165. 
afirmaciones como las de Ayala Mora, quien considera que las comunidades negras participaron en la guerra cuando fueron conscientes de que podrían alcanzar la libertad e incluso ascender socialmente, siempre y cuando se alistasen en el ejército patriota ${ }^{87}$. Cabe informar que este juego propagandístico del ofrecimiento de libertad y ascenso social no fue un monopolio exclusivo de los insurgentes, pues los realistas también ofrecieron a las comunidades negras la posibilidad de ser libres a cambio de su participación como soldados del ejército realista ${ }^{88}$.

En este análisis del protagonismo étnico hay dos autores (Holguín y Muñoz) que definen a los indígenas como actores principales de la Independencia. No obstante, dicho protagonismo radica en su condición de víctimas de la opresión del sistema colonial y no como héroes de la gesta independentista. Tomando como punto de partida investigaciones historiográficas actualizadas debemos informar que, en contraposición a lo propuesto por los textos escolares, la realidad del indígena en el periodo colonial no se basó exclusivamente en una relación con los peninsulares articulada a partir de la dualidad vencedor/vencido, explotador/explotado ${ }^{89}$. Cabe recordar que a lo largo del siglo XVII y principios del XVIII, la sociedad indígena representada por la República de Indios disfrutaba de una amplia permisibilidad ${ }^{90}$, tenían derecho a poseer sus propias lenguas, culturas, leyes, tradiciones y tierras ${ }^{91}$.

A partir de investigaciones historiográficas realizadas en los últimos años sobre el protagonismo del indígena en el sistema colonial hispano, se pueden someter a debate argumentos como los de Holguín quien afirma que los indígenas al ser un grupo étnico inferior tuvieron un gran protagonismo en el desarrollo de un sentimiento de descontento hacia la Corona ${ }^{92}$, o como los de Muñoz quien considera que los indígenas al ser durante tres siglos humillados y explotados buscaron la Independencia para liberarse del dominio español ${ }^{93}$. Estas interpretaciones pueden ser sometidas a debate en la actualidad ya que el protagonismo del indígena en la época colonial no se redujo exclusivamente a ser una víctima o un esclavo. Cabe recordar que la Corona hispana fue la única que convirtió a los habitantes del Nuevo Mundo en vasallos del rey ${ }^{94}$. Es cierto que la Conquista alteró la realidad de los nativos amerindios, pero esto no supuso un inmovilismo. En algunos casos, los indígenas se adaptaron a la nueva realidad y lucharon para alcanzar sus objetivos

\footnotetext{
${ }^{87}$ AYALA MORA, Enrique. Estudios Sociales 6... Op. cit., p. 87.

${ }^{88}$ RUEDA NOVOA, Rocío. Esclavos y negros libres en Esmeraldas s. XVIII-XIX. Procesos. Revista Ecuatoriana de Historia. 2001, n. 16, pp. 25-31.

${ }^{89}$ CHÁVEZ, María Eugenia. Los sectores subalternos y la retorica libertaria. Esclavitud e inferioridad racial en la gesta independentista. En: BUSTOS, Guillermo y MARTÍNEZ, Armando (eds.). La Independencia en los Países Andinos: Nuevas perspectivas. Bucaramanga: Universidad Andina Simón Bolívar; Organización de Estados Iberoamericanos, 2004, pp. 209-218.

90 RODRÍGUEZ ORDÓÑEZ, Jaime. La Revolución de la Independencia Hispanoamericana frente a las Revoluciones Atlánticas. Perspectivas comparativas. En: BUSTOS, Guillermo y MARTíNEZ, Armando (eds.). La Independencia en los Países Andinos: Nuevas perspectivas. Bucaramanga: Universidad Andina Simón Bolívar; Organización de Estados Iberoamericanos, 2004, pp. 18-19.

91 PIETSCHMANN, Horts. Las élites políticas de México en la época de la emancipación, 1770-1830. En: TÁUREGUI, Luis y SERRANO, José Antonio (eds.). Historia y nación. México: El Colegio de México, 1998, p. 58.

92 HOLGUÍN ARIAS, Rubén. Estudios Sociales 5... Op. cit., pp. 66-76.

${ }^{93}$ MUÑOZ, Hernán. Estudios Sociales... Op. cit., pp. 112-115.

94 PÉREZ HERRERO, Pedro. La América Colonial (1492-1763). Política y Sociedad. Madrid: Síntesis, 2002, p. 72.
} 
utilizando, por ejemplo, las propias instituciones coloniales. El estudio de Carlos Ciriza acerca de los testamentos de indígenas quiteños del siglo XVII podría ser una gran herramienta para reflexionar sobre el protagonismo del indígena en la época colonial. Este autor, mediante el estudio del testamento de la indígena quiteña María de Sinachimbo, ha descubierto que se ha generado en torno a ella una importante red de deudores que le ha permitido extender sus conexiones y vínculos personales más allá de la población indígena ${ }^{95}$. Sinachimbo es un ejemplo clave para plantear un debate en torno a esa supuesta dominación ejercida por los peninsulares (presente en los textos escolares) contra los nativos amerindios a lo largo de tres siglos.

\section{Consideraciones finales}

El uso público de la Historia en el proceso de creación y de imaginación de identidades sociales, políticas y culturales ha estado unido al nacimiento de los Estados-nación ${ }^{96}$. Es por esta razón que desde el siglo XIX hasta la actualidad, la enseñanza de la Independencia del Ecuador ha estado sujeta a los objetivos políticos establecidos por las reformas curriculares de los diferentes gobiernos, y las editoriales que publican los textos escolares deben acogerse a lo estipulado por las leyes educativas en lo referente al estudio de la Independencia. Esta situación ha provocado que los textos escolares hayan sido utilizados como instrumentos ideológicos para construir una identidad nacional, mostrando continuidad en una explicación de la Independencia ecuatoriana que se gestó en los planteamientos de la Historia Patria surgida en el siglo XIX.

La utilización de la enseñanza de la Independencia para consolidar esa identidad nacional del siglo XIX se hace patente en este análisis sobre el protagonismo de los distintos grupos étnicos en la Independencia. Acorde a lo propuesto por la Historia Patria, en este análisis se ha podido apreciar que los textos escolares explican la Independencia como un proyecto de construcción nacional dirigido exclusivamente por las élites criollas, cuyo supuesto principal objetivo era conseguir la libertad para la Patria. Pese a que hay autores que han denunciado que indígenas, negros, mestizos, zambos, pardos y mulatos obtuvieron pocos beneficios de la Independencia, todos los textos escolares no dudan en confirmar que gracias a los esfuerzos de las élites criollas el Ecuador pudo ser libre.

Después del recuento realizado sobre el protagonismo de los distintos grupos étnicos, a lo largo de este trabajo se ha podido apreciar que el gran protagonismo otorgado a criollos y peninsulares, frente al papel secundario de indígenas, negros, zambos, pardos, mulatos, etc., coincide con los datos propuestos por las investigaciones académicas recientes, donde se manifiesta que la Independencia fue un acontecimiento que enfrentó a criollos versus peninsulares. No obstante, los

95 CIRIZA-MENDíVIL, Carlos. Los indígenas quiteños a través de sus testamentos: dinámicas socioculturales en el siglo XVII. Procesos. Revista Ecuatoriana de Historia. 2017, n. 45, pp. 11-12.

96 GÓMEZ CARRASCO, Cosme J. y RODRíGUEZ PÉREZ, Raimundo A. La enseñanza de la Historia y el uso de libros de texto ante los retos del siglo XXI. Entrevista a Rafael Valls Montés. Historia y Memoria de la Educación. 2017, n. 6, p. 364. 
textos escolares en su labor por lograr la consolidación de esa ansiada identidad nacional no justifican el gran protagonismo de unos y el escaso de otros; ni tampoco el título otorgado a las élites criollas como los héroes y arquitectos de la Patria, así como la catalogación del peninsular como enemigo de la naciente República. Ante este vacío de respuestas, proponemos la vinculación de las nuevas líneas de investigación académica sobre la Independencia a la enseñanza escolar de la Historia por medio de una transposición didáctica del saber sabio (investigaciones académicas actuales), al saber enseñado (textos escolares). Es decir, una transformación de las teorías elaboradas por las investigaciones académicas en un objeto que se pueda enseñar a los educandos, terminando con la utilización de la enseñanza de la Historia para construir una nación y una identidad propias del siglo $\mathrm{XIX}^{97}$.

La importancia de esta propuesta radica en que, por medio de esta transformación de las investigaciones académicas en un objeto de enseñanza, se puede someter a debate la interpretación realizada por la Historia Patria del siglo XIX sobre la Guerra de Independencia (presente en los textos escolares) como una contienda que enfrentó a dos naciones e identidades. Los textos escolares no aportan una explicación elaborada sobre el porqué del gran protagonismo de criollos y peninsulares y del escaso protagonismo de indígenas, negros, zambos, etc., dado que el objetivo de esta Historia Patria desde el siglo XIX fue evitar que la Guerra de Independencia sea estudiada como una guerra civil. Según Pérez Vejo, este objetivo, que se ha mantenido en el tiempo, fue el mismo que se propusieron las élites criollas patriotas tras obtener el triunfo en la Guerra de Independencia. Los líderes criollos a través de los medios de comunicación de la época pusieron en marcha la construcción imaginaria del español como enemigo de la nación, haciéndolo culpable de todas las desigualdades sociales, económicas y étnicas. Por medio de este proceso de hispanofobia, los criollos insurgentes realizaron su propia interpretación de la Independencia como una guerra anticolonial donde el ecuatoriano se enfrentó a un supuesto enemigo extranjero: el español98.

Este sentimiento de hispanofobia, que forma parte de la Historia Patria del siglo XIX, sigue teniendo mucha presencia tanto en la Historia enseñada (presente en los cien años de textos escolares analizados) como en el discurso político y público del Ecuador. Con esta propuesta de utilización de las investigaciones académicas en el espacio educativo buscamos promover el estudio de la Independencia a nivel escolar tomando como referencia las obras de historiadores como Chust y Frasquet, quienes afirman que la gesta de Independencia sirvió para construir una República blanca y criolla99. De esta manera, se podría someter a debate la definición de la

97 Una explicación más detalla de esta propuesta de transposición didáctica se encuentra en SILVA GUIJARRO, Víctor H. Republicanos versus absolutistas. Análisis ideológico de la Independencia ecuatoriana en los textos escolares de Historia (1915-2015). Una propuesta desde el paradigma de la transposición didáctica. En: La llusión Heroica. El liberalismo revolucionario en España y América, 1820-1823. Santiago de Chile: Editorial Ariadna, 2021 [en prensa].

98 PÉREZ VEJO, Tomás. La hispanofobia como elemento de movilización en las guerras de Independencia. ¿Un mito historiográfico? En: SÁNCHEZ CUERVO, Antolín y VELASCO GÓMEZ, Ambrosio (eds.). Filosofía política de las Independencias latinoamericanas. Madrid: Biblioteca Nueva, 2012, pp. 226-234.

99 CHUST, Manuel y FRASQUET, Ivana. Tiempos de Revolución: Comprender Las Independencias Iberoamericanas. Madrid: Fundación MAPFRE, 2013, p. 317. 
Independencia realizada por los textos escolares como el origen de una época de libertad para todos los ecuatorianos. Pues una vez consolidadas dichas repúblicas blancas y criollas mediante un proyecto unitario, el protagonismo político, económico y comercial se convirtió en un monopolio exclusivo para los criollos ${ }^{100}$; mientras que los indígenas, negros, zambos, mulatos, etc., desaparecieron de los proyectos republicanos del siglo XIX'101.

Asimismo, esta propuesta se podría convertir en una herramienta para lograr definitivamente el estudio de la Independencia a nivel educativo acorde a los planteamientos de Xavier Guerra ${ }^{102}$ o Jaime Rodríguez ${ }^{103}$, quienes definen este acontecimiento como una guerra civil que enfrentó a españoles peninsulares contra españoles americanos; o la tesis propuesta por Pérez Vejo, quien se adhiere a la explicación de la Independencia como una guerra civil, aunque este autor plantea que fue una guerra civil que enfrentó a americanos versus americanos ${ }^{104}$. El estudio de la Independencia como una guerra civil, evitado por la Historia Patria, da respuesta tanto al protagonismo principal otorgado por los textos escolares a los criollos y peninsulares, como al escaso protagonismo de indígenas, negros, zambos, etc., pues la Independencia, en contraposición a lo propuesto por los textos escolares, fue un acontecimiento liderado por las élites criollas que aceleró el desarrollo de una revolución política y militar, pero retrasó la consolidación de la igualdad y libertad social para todos los grupos étnicos en las nuevas Repúblicas ${ }^{105}$.

Sin embargo, la propuesta de vinculación de las nuevas líneas de investigación académica sobre la Independencia a la enseñanza escolar de la Historia es un tema complejo, pues ello supondría romper con los imaginarios nacionales que han estado presentes en los textos escolares desde el siglo XIX. Además, de esa forma se dificultaría el afianzamiento del objetivo principal de dichos textos, consistente en la construcción del Estado-nación y la creación de una identidad nacional ideada por las élites criollas en el siglo XIX, en detrimento de la consolidación de una sociedad formada por ciudadanos más analíticos y críticos ${ }^{106}$. No obstante, en la actualidad esa idea de identidad y de Estado-nación está en peligro por dos motivos; por el proceso de globalización que dificulta mantener unas fronteras nacionales, y por las

100 REYES, Catalina. La fragmentación étnica y política y su incidencia en la Independencia de la Nueva Granada, 1750-1815. En: MARTíNEZ, Armando (ed.). Independencia y transición a los Estados Nacionales en los países andinos: Nuevas perspectivas. Bogotá: Organización de Estados Iberoamericanos, 2005, p. 315.

101 ALMARIO GARCÍA, Óscar. Racialización, etnicidad y ciudadanía en el Pacífico neogranadino, 1780-1830. En: MARTíNEZ, Armando (ed.). Independencia y transición a los Estados Nacionales en los países andinos: Nuevas perspectivas. Bogotá: Organización de Estados Iberoamericanos, 2005, pp. 317-352.

102 GUERRA, François-Xavier. La ruptura originaria: mutaciones, debates y mitos de la Independencia. En: CARRERA DAMAS, Germán [et al.] (eds.). Mitos políticos en las sociedades andinas. Orígenes, invenciones y ficciones. Caracas: Editorial Equinoccio, 2006, p. 28.

103 RODRÍGUEZ ORDÓÑEZ, Jaime. Las Independencias lberoamericanas en su laberinto. En: CHUST, Manuel (ed.). La Independencias Iberoamericanas en su laberinto. Controversias, cuestiones, interpretaciones. Valencia: Publicaciones Universidad de Valencia, 2010, pp. 311-316.

104 PÉREZ VEJO, Tomás. La hispanofobia... Op. cit., pp. 232-235.

105 ALMARIO GARCÍA, Oscar. Racialización, etnicidad... Op. cit., pp. 317-352.

106 GÓMEZ CARRASCO, Cosme J. y RODRíGUEZ PÉREZ, Raimundo A. La enseñanza de la Historia... Op. cit., pp. 317-375. 
fuerzas locales y regionales, así como de los diversos grupos étnicos que reclaman un mayor protagonismo en el desarrollo de la vida nacional ${ }^{107}$. Desde nuestro punto de vista, el problema del concepto de identidad nacional del siglo XIX reside en que es una idea anacrónica que no cumple con las exigencias que demanda la sociedad actual. Cabe recordar que ese Estado-nación surgido de la ruptura del sistema colonial no cumplió con las reivindicaciones de libertad de todos los grupos étnicos, ya que fue un proyecto creado por y para las élites criollas. Ante esta situación, a través de este análisis de los textos escolares (en consonancia con las nuevas líneas de investigación) buscamos promover la enseñanza de una nueva identidad nacional en la que todas las realidades sociales, étnicas, políticas, económicas, etc., que conforman la actual República del Ecuador tengan cabida ${ }^{108}$.

Pese a las adversidades y gracias a los esfuerzos realizados por las investigaciones académicas, consideramos que el primer paso para superar el arraigo de la Historia Patria del siglo XIX empieza por desarticular una de sus máximas: explicar el pasado desde una perspectiva histórica encerrada en sus propias fronteras nacionales ${ }^{109}$. Esta situación impide levantar una mirada a las demás realidades históricas latinoamericanas. El segundo paso es el reconocimiento de que, sin embargo, la historia ecuatoriana no puede escribirse en clave antinacional porque sigue siendo un país en construcción identitaria, el cual, necesita crear sus propios héroes y mitos para unificar a la ciudadanía. La sociedad ecuatoriana ha entendido que no tiene una identidad, sino varias. Esta situación debe conducir a una necesaria reforma del concepto de identidad nacional transmitido por los textos escolares ${ }^{110}$ mediante esta propuesta de transposición didáctica.

A lo largo de esta investigación se ha podido apreciar que el análisis crítico sobre el proceso de emancipación no es aceptado. Por esta razón, los textos escolares siguen manteniendo la tesis de la Historia Patria sobre la explicación de la Independencia como un acontecimiento supremo que trajo consigo el nacimiento de la República del Ecuador gracias a los esfuerzos de los libertadores. Ante esta situación, consideramos que una de las posibles formas para lograr la reforma de la Historia Patria del siglo XIX se encuentra en ceder el control de la enseñanza de la Historia a los investigadores académicos expertos. A cambio, estos elaborarían una nueva Historia Patria la cual, tomando como referencia la obra de Ayala Mora, tendrá que superar las perspectivas tradicionales mediante un estudio de los diversos proyectos nacionales, asumiendo la creación de un proyecto nacional de futuro ${ }^{111}$ que permita la consolidación de una nueva identidad nacional más inclusiva y articulada a partir de los debates académicos actuales.

Ya para concluir, a través de este nexo entre la Historia enseñada y las investigaciones historiográficas académicas se podría llevar a cabo una remodelación del texto escolar de historia para transformarlo en un instrumento generador de pensamiento y conciencia crítica del pasado; y lograr la difusión a nivel

\footnotetext{
107 AYALA MORA, Enrique. Historiografía ecuatoriana... Op. cit., pp. 19-20.

108 Ibídem, pp. 19-20.

109 lbídem, p. 20.

110 Ibídem, pp. 20-21.

111 Ibídem, p. 21.
} 
educativo de una explicación de la Independencia del Ecuador desde una perspectiva cultural e integracionista ${ }^{112}$, dejando en un segundo plano la utilización de la Historia Patria del siglo XIX como una herramienta nacionalista para llevar a cabo una "ecuatorianización" de los periodos aborigen, colonial e independentista ${ }^{113}$.

\section{Bibliografía}

\subsection{Textos escolares analizados}

AYALA MORA, Enrique. Estudios Sociales 6. Historia Del Ecuador I. Época Aborigen, Colonia e Independencia. Quito: Corporación Editora Nacional, 2010.

BRUÑO, G. M. Compendio de la Historia del Ecuador. Ecuador: Hermanos de las Escuelas Cristianas, 1915.

BRUÑO, G. M. Resúmenes de la Historia del Ecuador. Ecuador: Hermanos de las Escuelas Cristianas, 1916.

CANO, F. A. Nociones elementales de Historia del Ecuador. Ecuador: Prensa Católica, 1920.

CARRILLO DE LANDÁZURI, Rogelia. El libro del Escolar Ecuatoriano 6. Quito: Edimpres, 1997.

CEVALLOS GARCÍA, Gabriel. Historia del Ecuador 5ำ Curso. Ciclo Diversificado. Cuenca: Don Bosco, 1972.

CEVALLOS GARCÍA, Gabriel. Historia del Ecuador 5ำ Curso. Colección LNS. Cuenca: Don Bosco, 1978.

CRUZ, Katherine de la y RUANO GÓMEZ, Olver. Enigmas I. Historia y Ciencias Sociales. Guayaquil: Argo, 2015.

HOLGUÍN ARIAS, Rubén. Estudios Sociales 5. Quito: Holguín Ediciones, 2003.

Ministerio de Educación. Estudios Sociales 9. Pichincha: Gobierno de Pichincha, 2008.

MOSCOSO, Leonardo. Lecciones Elementales de la Historia General del Ecuador. Quito: J. Roberto Cruz, 1934.

MUÑOZ, Hernán. Estudios Sociales. Quito: Prolipa, 2007.

112 CAJÍAS DE LA VEGA, Magdalena. La Independencia frente a la integración latinoamericana en los textos escolares. En: BUSTOS, Guillermo y MARTÍNEZ, Armando (eds.). La Independencia en los Países Andinos: Nuevas perspectivas. Bucaramanga: Universidad Andina Simón Bolívar; Organización de Estados Iberoamericanos, 2004, pp. 252-254.

113 BUSTOS, Guillermo. El culto a la nación. Escritura de la historia y rituales de la memoria en Ecuador, 1870-1950. Quito: FCE; Universidad Andina Simón Bolívar, 2017, pp. 273-274. 
NAVAS JIMÉNEZ, Mario. Estudios Sociales 9. Quito: Quebecor World Bogotá, 2001.

NÚÑEZ SÁNCHEZ, Jorge. Historia del Ecuador. Quito: Santillana, 1997.

UZCÁTEGUI García, Emilio. Historia del Ecuador. Texto para la Enseñanza de Historia Patria. Quito: Editorial Bolívar, 1929.

\subsection{Referencias bibliográficas}

ALMARIO GARCÍA, Óscar. Racialización, etnicidad y ciudadanía en el Pacífico neogranadino, 1780-1830. En: MARTíNEZ, Armando (ed.). Independencia y transición a los Estados Nacionales en los países andinos: Nuevas perspectivas. Bogotá: Organización de Estados Iberoamericanos, 2005, pp. 317-370.

AYALA MORA, Enrique. Historia del Ecuador II. Época Republicana. Quito: Corporación Editora Nacional, 2015.

AYALA MORA, Enrique. Historiografía ecuatoriana: apuntes para una visión general. Quito: Corporación Editora Nacional, 2015.

BERNAL RUIZ, Graciela. Sociedad y guerra: actitudes ante la insurgencia en San Luis Potosí, 1810-1821. En: ÁLVAREZ CUARTERO, Izaskun y SÁNCHEZ GÓMEZ, Julio (eds.). Visiones y revisiones de la Independencia de América. México, Centroamérica y Haití. Salamanca: Ediciones Universidad de Salamanca, 2005, pp. 157-178.

BOYD, Carolyn P. Historia Patria. Política, historia e identidad nacional en España: 1875-1975. Barcelona: Ediciones Pomares-Corredor, 2000.

BUSTOS, Guillermo. El culto a la nación. Escritura de la historia y rituales de la memoria en Ecuador, 1870-1950. Quito: FCE; Universidad Andina Simón Bolívar, 2017.

CAJÍAS DE LA VEGA, Magdalena. La Independencia frente a la integración latinoamericana en los textos escolares. En: BUSTOS, Guillermo y MARTÍNEZ, Armando (eds.). La Independencia en los Países Andinos: Nuevas perspectivas. Bucaramanga: Universidad Andina Simón Bolívar; Organización de Estados Iberoamericanos, 2004, pp. 246-254.

CARRETERO, Mario. La construcción de una identidad nacional. Cuadernos de Pedagogía. 2001, n. 308, pp. 52-57.

CHÁVEZ, María Eugenia. Los sectores subalternos y la retorica libertaria. Esclavitud e inferioridad racial en la gesta independentista. En: BUSTOS, Guillermo y MARTíNEZ, Armando (eds.). La Independencia en los Países Andinos: Nuevas perspectivas. Bucaramanga: Universidad Andina Simón Bolívar; Organización de Estados Iberoamericanos, 2004, pp. 209-218.

CHUST, Manuel y FRASQUET, Ivana. Tiempos de Revolución: Comprender Las 

2015).

Independencias Iberoamericanas. Madrid: Fundación MAPFRE, 2013.

CIRIZA-MENDÍVIL, Carlos. Los indígenas quiteños a través de sus testamentos: dinámicas socioculturales en el siglo XVII. Procesos. Revista Ecuatoriana de Historia. 2017, n. 45, pp. 9-34.

CRUZ FERNÁNDEZ, Paula de la. Enseñando identidad nacional en el Ecuador. Minius: Revista de Departamento de Historia, Arte e Xeografía. 2008, n. 16, pp. 113-134.

CUESTA, Raimundo. El código disciplinar de la Historia escolar en España: Algunas ideas para la explicación de la sociogénesis de una materia de enseñanza. Encounters in Theory and History of Education. 2002, n. 3, pp. 27-41.

GÓMEZ CARRASCO, Cosme J. y RODRíGUEZ PÉREZ, Raimundo A. La enseñanza de la Historia y el uso de libros de texto ante los retos del siglo XXI. Entrevista a Rafael Valls Montés. Historia y Memoria de la Educación. 2017, n. 6, pp. 363-380.

GUERRA, François-Xavier. La ruptura originaria: mutaciones, debates y mitos de la Independencia. En: CARRERA DAMAS, Germán [et al.] (eds.). Mitos políticos en las sociedades andinas. Orígenes, invenciones y ficciones. Caracas: Editorial Equinoccio, 2006, pp. 21-42.

OSSENBACH, Gabriela. Formación de los sistemas educativos nacionales en Hispanoamérica. El caso ecuatoriano, 1895-1912. Quito: Corporación Editorial Nacional, 2018.

OSSENBACH, Gabriela. La secularización del sistema educativo y de la práctica pedagógica: laicismo y nacionalismo. Procesos. Revista Ecuatoriana de Historia. 1996, n. 8, pp. 33-54.

PÉREZ HeRRERO, Pedro. La América Colonial (1492-1763). Política y Sociedad. Madrid: Síntesis, 2002.

PÉREZ VEJO, Tomás. España imaginada: historia de la invención de una nación. Barcelona: Galaxia Gutenberg, 2015.

PÉREZ VEJO, Tomás. La hispanofobia como elemento de movilización en las guerras de Independencia. ¿Un mito historiográfico? En: SÁNCHEZ CUERVO, Antolín y VELASCO GÓMEZ, Ambrosio (eds.). Filosofía política de las Independencias latinoamericanas. Madrid: Biblioteca Nueva, 2012, pp. 219-235.

PÉREZ VEJO, Tomás. Nación, identidad nacional y otros mitos nacionalistas. Oviedo: Ediciones Nobel, 1999.

PIETSCHMANN, Horts. Las élites políticas de México en la época de la emancipación, 1770-1830. En: TÁUREGUI, Luis y SERRANO, José Antonio 
(eds.). Historia y nación. México: El Colegio de México, 1998, pp. 45-63.

REYES, Catalina. La fragmentación étnica y política y su incidencia en la Independencia de la Nueva Granada, 1750-1815. En: MARTíNEZ, Armando (ed.). Independencia y transición a los Estados Nacionales en los países andinos: Nuevas perspectivas. Bogotá: Organización de Estados Iberoamericanos, 2005, pp. 281-316.

RODRÍGUEZ ORDÓÑEZ, Jaime. La Revolución de la Independencia Hispanoamericana frente a las Revoluciones Atlánticas. Perspectivas comparativas. En: BUSTOS, Guillermo y MARTÍNEZ, Armando (eds.). La Independencia en los Países Andinos: Nuevas perspectivas. Bucaramanga: Universidad Andina Simón Bolívar; Organización de Estados Iberoamericanos, 2004, pp. 15-40.

RODRÍGUEZ ORDÓÑEZ, Jaime. Las Independencias Iberoamericanas en su laberinto. En: CHUST, Manuel (ed.). La Independencias Iberoamericanas en su laberinto. Controversias, cuestiones, interpretaciones. Valencia: Publicaciones Universidad de Valencia, 2010, pp. 311-316.

RUEDA NOVOA, Rocío. Esclavos y negros libres en Esmeraldas s. XVIII-XIX. Procesos. Revista Ecuatoriana de Historia. 2001, n. 16, pp. 3-33.

SILVA GUIJARRO, Víctor H. Republicanos versus absolutistas. Análisis ideológico de la Independencia ecuatoriana en los textos escolares de Historia (1915-2015). Una propuesta desde el paradigma de la transposición didáctica. En: La Ilusión Heroica. El liberalismo revolucionario en España y América, 1820-1823. Santiago de Chile: Editorial Ariadna, 2021 [en prensa]. 